\title{
Arteriography of the coeliac axis and superior mesenteric artery in five cases of haemochromatosis with particular regard to the pancreatic circulation
}

\author{
L. A. SCURo \\ M.D.
}

\begin{abstract}
R. ZUIN
M.D.

Summary

Arteriography of the coeliac axis and superior mesenteric artery in five patients with haemochromatosis revealed a constant deficit of pancreatic vascularization as shown by reduced visualization of the arterial circle. These consistent results appear to be significant. There was no correlation between the existence and severity of diabetes mellitus and the pancreatic vascular involvement.
\end{abstract}

G. Curri

M.D.
G. MONTI
M.D.

S. RoMANI

M.D.

Istituto di Patologia Speciale Medica, di Clinica Medica e di Radiologia Medica dell'
Università di Padova, Italy

\section{Introduction}

The selective arteriography of the ventral collaterals of the abdominal aorta has contributed considerably to knowledge of vascular pathology as well as that of the accompanying visceral lesions.

These studies have made numerous contributions to knowledge of spleno-hepatic (Morino, Tarquini \& Ölivero, 1956; Ödman, 1958, 1961 ; Olsson, 1964 ; Acker, 1964 ; Glenn, 1965), pancreatic (Olsson, 1965 ; Rösch \& Brett, 1965 ; Lunderquist, 1965 \& Rösch, 1966) and intestinal pathology (Olivero, 1958; Margulis \& Heinbecker, 1961 ; Ström \& Windberg, 1962; Boijsen \& Reuter, 1966).

The use of pharmacological stimulants later permitted a minute functional examination of the vessels. Thus, Ödman (1961), Taylor, Machen \& Fiore (1966) and particularly Lenarduzzi, Romani \& Zacchi (1967), studying the behaviour of the pancreatic vessels after injection of secretin, have observed that in a normal subject there is an increase of vascularization which may or may not be absent in conditions with pancreatic pathology. The use of secretin has been particularly useful for the angiographic study of pancreatitis, in which condition vascular damage to the organ is evident.

It is known that in many cases of haemo. chromatosis, particularly in the primary 'idiopathic' form, as with chronic hepatitis and cirrhosis a sclerosis of the pancreas occurs, which manifests itself clinically by diabetes. In some patients affected with primary or secondary hepatic haemochromatosis it seemed of great interest to investigate the behaviour of the pancreatic vasculature.

\section{Methods}

It appears that similar researches have not been conducted previously. Four patients with primary haemochromatosis and one with secondary haemochromatosis were therefore subjected to arteriography of the coeliac axis; the behaviour of the pancreatic circulation was then studied in three of these cases after stimulation with secretin.

The main laboratory findings in the five patients examined are reported in Table 1. In the case of secondary haemochromatosis (No. 5) diabetes mellitus was not present; in one case (No. 1) diabetes mellitus was of very moderate severity.

The clinical findings and radiological investigations of the digestive and biliary tracts are reported in Table 2 . It must be pointed out that in each case after intravenous cholangiography the biliary tracts were not visualized. Since in some cases there were no definite signs of either liver pathology or of definite gall bladder disease, this is difficult to explain.

The angiographic methods used in each case are reported in Table 3. 2 I.U./kg of secretin (Vitrum) was administered to three patients 
through a catheter placed within the coeliac axis. The angiographic techniques are summarized in Table 4.

\section{Results}

A comparison was made in a normal subject between arteriographs of the coeliac axis before and after secretin stimulation (see Fig. 1). A moderate increase of vascularization was observed after hormonal injection through the catheter.

In the five cases of haemochromatosis, the most striking results were found in the angiography of the pancreatic circulation, while the changes in the hepatic, splenic and mesenteric circulations were moderate. The only manifestation of hepato-splenomegaly was the extension of the arterial intra-parenchymal ramifications (Figs. 2-4) with displacement (towards the left) of the pancreatico-duodenal artery and sometimes of the whole coeliac axis. No definite evidence of significant damage to these arteries has been observed either in their extra- or intraparenchymal distribution. In the latter, though, some signs of rigidity and distortion of individual vessels could be noted. Opacification of the capillaries of these organs was fairly uniform, if not dense; a venous phase was also visible.

With regard to the pancreas, the observations have been more significant and unequivocal. An obvious disparity between the size and good visualization of the gastroduodenal artery and the poor visualization of its arterial ramifications round the head of the pancreas was noted. The pancreatic ramifications derived from the splenic and superior mesenteric arteries were also absent or barely visible. In the parenchymatous phase, following the poor filling of the pancreatic arteries, no opacification of the pancreas could be demonstrated. These findings were not modified by the succeeding secretin injections through the catheter in the three cases in which catheterization of the artery was possible.

The uniformity of these findings of poor or absent visualization of the pancreatic arteries in the five cases studied shows that there is no correlation with the degree of pancreatic damage suggested by the severity of diabetes. In fact, in two subjects (Nos. 1 and 5), where diabetes was absent or moderate, there was poor visualization of almost all the pancreatic vessels; the angiographic picture was similar to that of the other three cases where the diabetes was more severe.

These results are interesting and suggest the need for further studies.

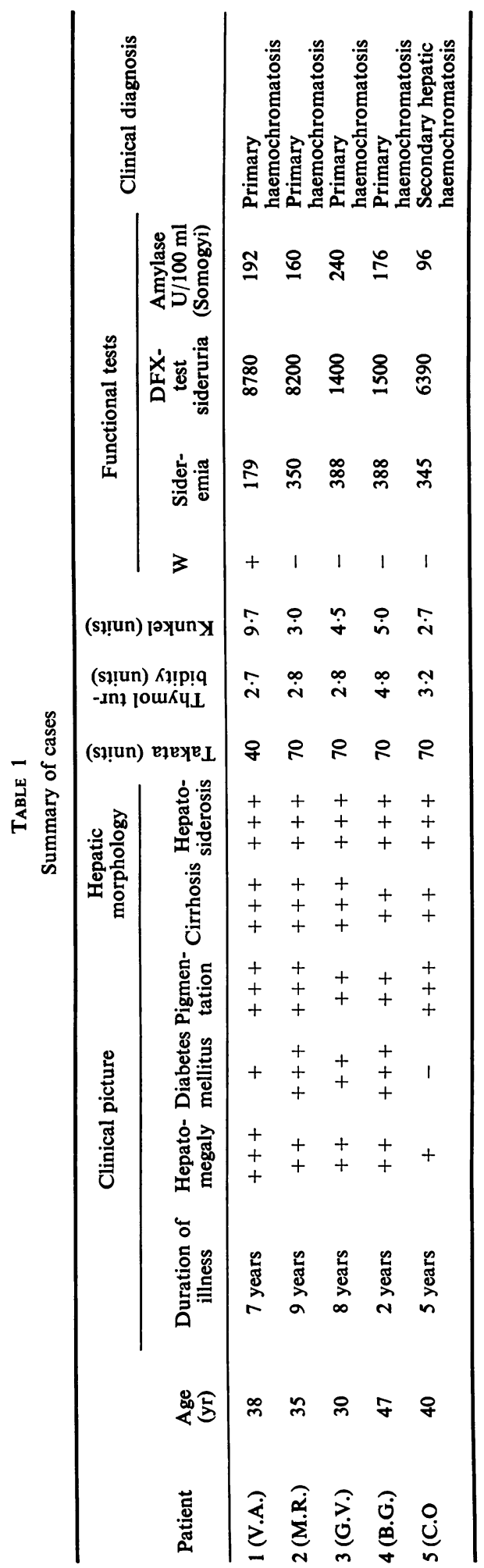


TABLE 2

Results of clinical and radiological examinations

\begin{tabular}{|c|c|c|c|c|c|}
\hline & \multicolumn{5}{|c|}{ Patient } \\
\hline & 1 (V.A.) & 2 (M.R.) & 3 (G.V.) & 4 (B.G.) & 5 (C.O.) \\
\hline Hepatomegaly & +++ & ++++ & +++ & +++ & +++ \\
\hline Splenomegaly & ++ & - & ++ & \pm & \pm \\
\hline Straight X-ray of the abdomen & Negative & Negative & Negative & Negative & Negative \\
\hline $\begin{array}{l}\text { X-ray examination of the gastro- } \\
\text { intestinal tract }\end{array}$ & $\begin{array}{l}\text { Oesophageal } \\
\text { varices }\end{array}$ & Negative & Negative & Negative & Negative \\
\hline Intravenous cholangiography & $\begin{array}{l}\text { Non- } \\
\text { visualization } \\
\text { of the biliary } \\
\text { ducts }\end{array}$ & $\begin{array}{l}\text { Non- } \\
\text { visualization } \\
\text { of the biliary } \\
\text { ducts }\end{array}$ & $\begin{array}{l}\text { Non- } \\
\text { visualization } \\
\text { of the biliary } \\
\text { ducts }\end{array}$ & $\begin{array}{l}\text { Non- } \\
\text { visualization } \\
\text { of the biliary } \\
\text { ducts }\end{array}$ & $\begin{array}{l}\text { Non- } \\
\text { visualiza tion } \\
\text { of the biliary } \\
\text { ducts }\end{array}$ \\
\hline
\end{tabular}

TABLE 3

Methods of examination in the angiographic exploration of the pancreas employed in each case

\begin{tabular}{|c|c|c|c|c|c|}
\hline & \multicolumn{5}{|c|}{ Patient } \\
\hline & 1 (V.A.) & 2 (M.R.) & 3 (G.V.) & 4 (B.G.) & 5 (C.O.) \\
\hline Superior mesenteric arteriography & - & + & + & - & - \\
\hline
\end{tabular}

*Also after stimulation with secretin (2 I.U./kg).

TABLE 4

Angiographic technique

Coeliac arteriography (transfemoral): $40 \mathrm{ml}$ Conray $60 \% 10 \mathrm{ml} / \mathrm{sec}$

Possible simultaneous sup. mesenteric arteriography: $30 \mathrm{ml}$ Conray $60 \% 10 \mathrm{ml} / \mathrm{sec}$

$3 \mathrm{films} / \mathrm{sec}$ for $3 \mathrm{sec}$-later $1 \mathrm{film} / 2 \mathrm{sec}$ up to $25 \mathrm{sec}$

$200 \mathrm{ml}$ intravenous mannitol

Secretin injection $2 \mathrm{U} / \mathrm{kg}$ in coeliac catheter

Coeliac arteriography (transfemoral)

Possible simultaneous sup. mesenteric arteriography

TABLE 5

Comparison between the severity of the disease and the evaluation of the vascular damage of the pancreas

\begin{tabular}{|c|c|c|c|c|c|}
\hline & \multicolumn{5}{|c|}{ Patient } \\
\hline & 1 (V.A.) & 2 (M.R.) & 3 (G.V.) & 4 (B.G.) & 5 (C.O.) \\
\hline Duration of the illness & 7 years & 9 years & 8 years & 2 years & 5 years \\
\hline Severity of the disease & ++++ & +++ & +++ & +++ & ++ \\
\hline Vascular damage of the pancreas & ++ & +++ & ++ & +++ & ++++ \\
\hline
\end{tabular}




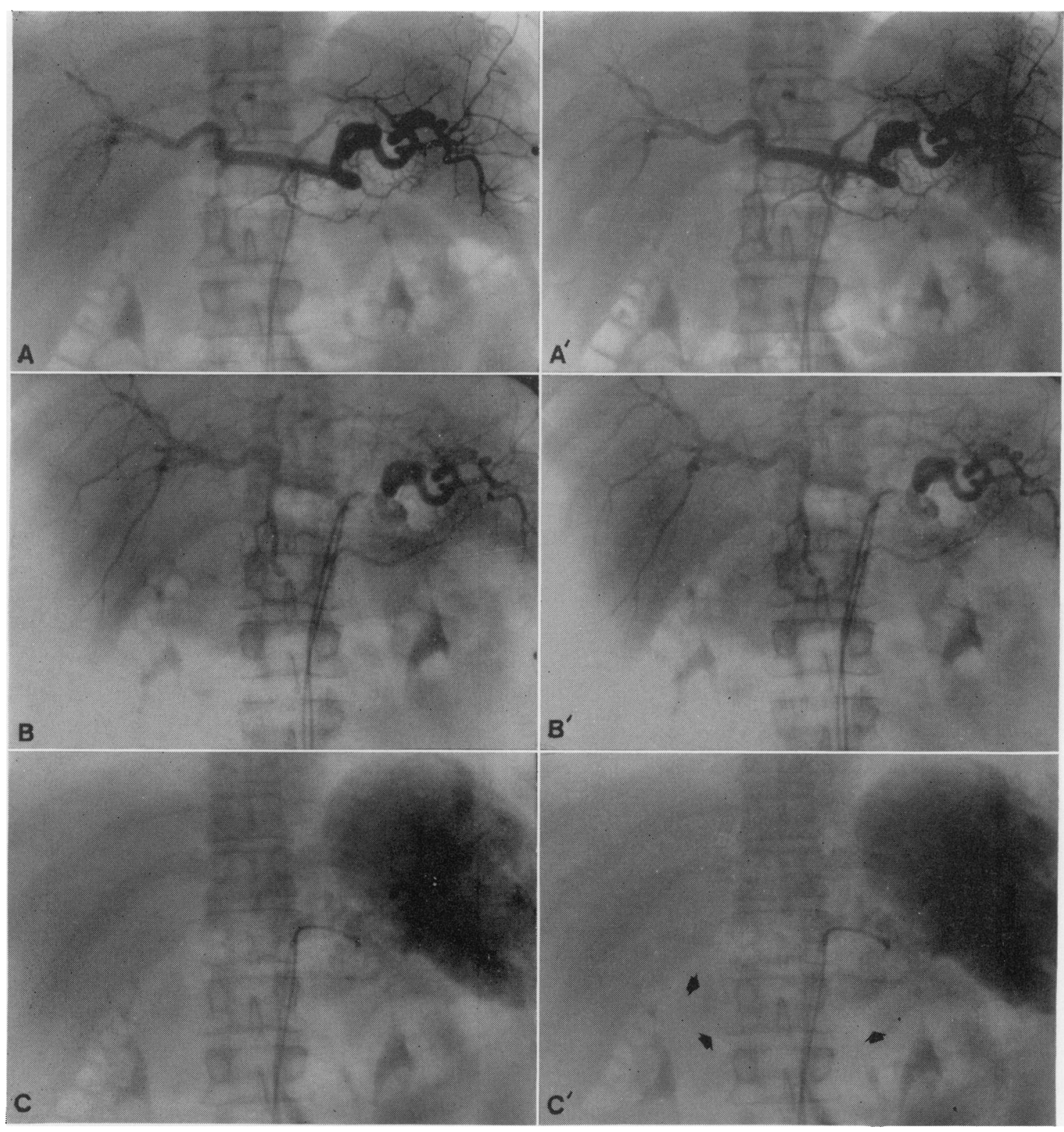

FIG. 1. Normal subject. Coeliac axis arteriography. (A) arterial phase; (B) arterial-capillary phase; (C) venouscapillary phase; $A^{\prime}, B^{\prime}, C^{\prime}$, the same phases after secretin. The arrows indicate the outline of the pancreas in $C^{\prime}$. 


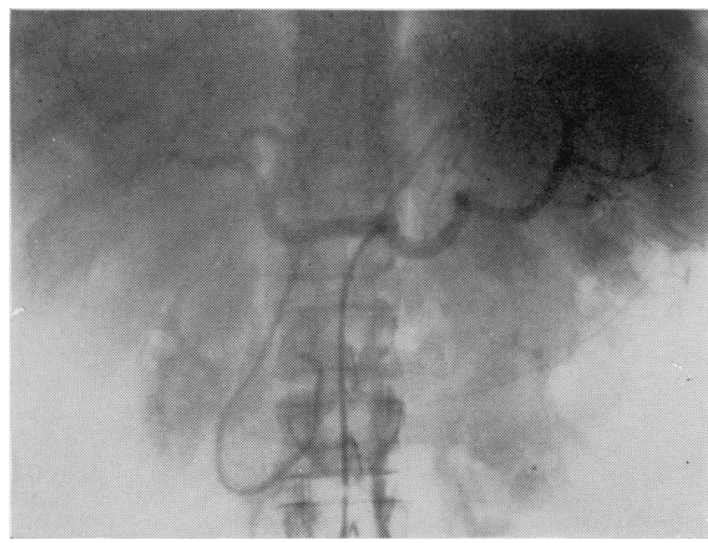

FIG. 2. Case 1. Coeliac axis arteriography. Arterial phase. No change was seen after the injection of secretin.

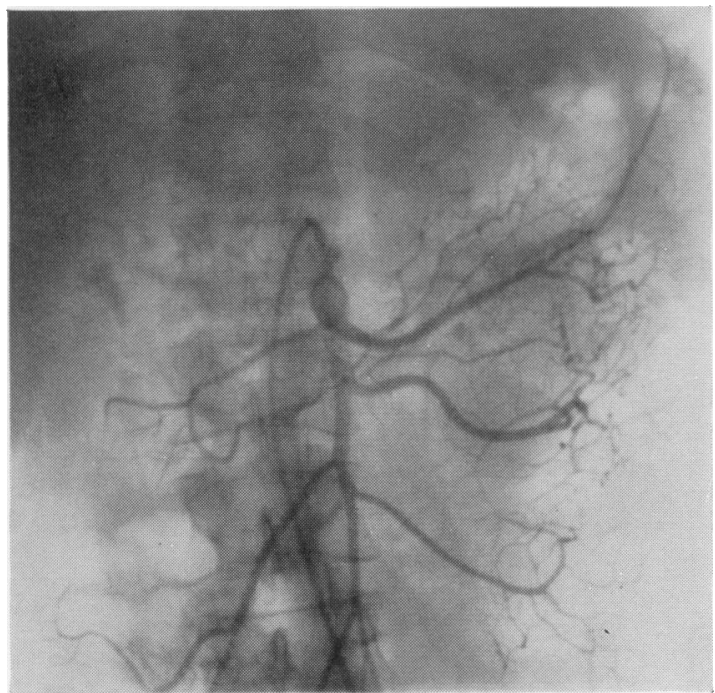

Fig. 3. Case 3. Superior mesenteric arteriography. Arterial phase.

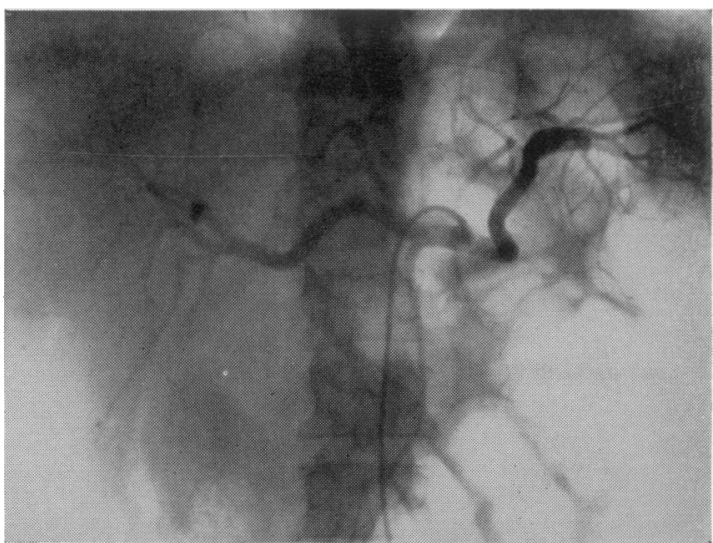

Fig. 4. Case 4. Coeliac axis arteriography. Arterial phase after secretin.

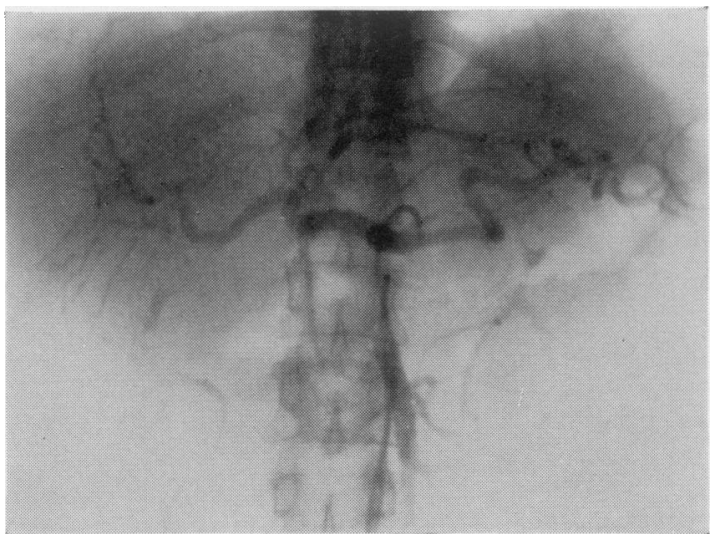

Fig. 5. Case 5. Arteriography of the coeliac axis and superior mesenteric. Arterial phase; no change was seen after injection of secretin. 


\section{References}

ACKer, J.J. (1964) Selective celiac angiography. Amer. J. Med. 37, 417.

Boisjen, E. \& Reuter, S. (1966) Mesenteric angiography in the evaluation of inflammatory and neoplastic disease of the intestine. Radiology, 87, 1028.

GlenN, F. (1965) Celiac and superior mesenteric arteriography. Rev. int. Hépat. 15, 337.

LenarduzzI, G., Romani, S. \& ZACCHI, C. (1967) La estimulation farmacologica de la function esocrina en la contrastografia opaca del pancreas. Atti VII Congr. Electroradiol. de Cultura Latina e I Congresso de la Asociacion Europea de Radiologia, Barcelona, 2-8 Avril 1967, p. 9. Talleres Graficos Agustin Nunez, Barcelona.

LUNDERQuist, A. (1965) Angiography in carcinoma of the pancreas. Acta radiol. (Stockh.), Suppl. 235.

Margulis, A.R. \& Heinbecker, P. (1961) Mesenteric arteriography. Amer. J. Roentgenol. 86, 103.

MORINo, F. (1960) L'arteriografia selettiva degli organi addominali. Minerva Medica, Torino.

Morino, F., TARquini, A. \& Olivero, S. (1956) Artériographie abdominale sélective par le cathétérisme de l'artère homérale. Presse méd. 64, 1944.
ODman, P. (1958) Percutaneous selective angiography of the celiac artery. Acta radiol. (Stockh.), Suppl. 159.

Ödman, P. (1961) Pancreatic angiography. Angiography (Ed. by H. L. Abrams), vol. 2, p. 627. Little-Brown, Boston.

Olivero, S. (1958) Arteriografia selettiva mesenterica superiore. Minerva cardioangiol. Suppl. 159.

OLsson, O. (1964) Celiacography. In: Progress in angiography. Thomas, Springfield, Illinois.

Olsson, O. (1965) Le diagnostic radiologique du pancréas. J. Radiol. Électrol. 46, 860.

Rösch, J. (1966) Angiographie du pancréas. Ann. Radiol. 9, 579.

Rösch, J. \& BRETT, J. (1965) Arteriography of the pancreas. Amer. J. Roentgenol. 94, 182.

Ström, B.G. \& Windberg, T. (1962) Percutaneous selective angiography of the inferior mesenteric artery. Acta radiol. (Stockh.), 57, 401.

TAYlor, D.A., Machen, K.L. \& Fiore, S.A. (1966) Angiographic visualization of the secretin-stimulated pancreas. Radiology, 87, 525. 